\title{
Massive Silicone Oil Migration into the Subconjunctival Space: A Leakage Mechanism Dilemma
}

\author{
Jesús Téllez ${ }^{a, c}$ José I. Vela ${ }^{a, b}$ Sabina Luna ${ }^{a, c}$ Rubén Delgado ${ }^{a}$ \\ aDepartment of Ophthalmology, Hospital de la Santa Creu i de Sant Pau, Autonoma \\ University of Barcelona, Barcelona, Spain; ${ }^{b}$ Department of Ophthalmology, Institut Condal \\ d'Oftalmologia, Barcelona, Spain; 'Departament of Ophthalmology, Grupo Admiravisión, \\ Barcelona, Spain
}

\section{Keywords}

Glaucoma drainage device $\cdot$ Silicone oil migration $\cdot$ Subconjunctival space $\cdot$ Sutureless vitrectomy

\begin{abstract}
Purpose: To report a case in which an early, massive silicone oil migration into the subconjunctival space occurred in a patient after sutureless vitrectomy with the presence of a previously implanted pars plana glaucoma drainage device. Case Report: An 80-year-old man presented with neovascular glaucoma secondary to a proliferative diabetic retinopathy in his left eye. After an intracamerular bevacizumab injection and panretinal photocoagulation, a 23gauge pars plana vitrectomy (PPV) combined with a superotemporal Ahmed pars plana glaucoma valve implantation was performed. Afterwards, the patient underwent a new 23-gauge PPV for a dense vitreous hemorrhage. Intravitreal 1,000 centistokes silicone oil was placed to prevent recurrent intraocular bleeding. No sutures were performed. In the first postoperative month, a massive migration of silicone oil into the $360^{\circ}$ subconjunctival space was noted until no intraocular silicone oil was observed. Conclusions: We discuss the possible leakage mechanisms in this particular case.

(C) 2018 The Author(s) Published by S. Karger AG, Basel
\end{abstract}




\section{Case Reports in Ophthalmology}

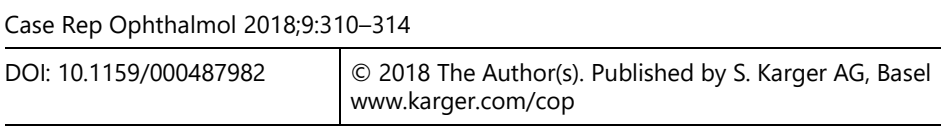

Téllez et al.: Massive Silicone Oil Migration into the Subconjunctival Space: A Leakage Mechanism Dilemma

\section{Introduction}

Neovascular glaucoma (NVG) is an end-stage complication of ischemic retinal vascular diseases like proliferative diabetic retinopathy or central retinal vein occlusion. Silicone oil (SO) has been used as an adjunct for internal tamponade in vitreoretinal surgery in these patients. On the other hand, it is often necessary to implant glaucoma drainage devices (GDDs) for the management of refractory NVG. Then, it is not uncommon to associate pars plana vitrectomy (PPV) with SO injection and glaucoma drainage implants.

We report a rare case in which an early, massive SO migration into the subconjunctival space occurred in a patient after sutureless PPV with the presence of a previously implanted pars plana GDD. We discuss the possible leakage mechanisms.

\section{Case Report}

An 80-year-old man without any known past medical history presented with NVG secondary to a proliferative diabetic retinopathy in his left pseudophakic eye. The patient received an intracamerular bevacizumab injection and panretinal photocoagulation. Afterwards, the patient underwent a 23-gauge PPV combined with a superotemporal Ahmed pars plana glaucoma valve implantation. A scleral patch with a fornix-based conjunctival flap was made and the tube was located in the vitreous cavity with complete success in intraocular pressure (IOP) control. Fifteen months after surgery, the patient underwent a new 23-gauge PPV for a dense vitreous hemorrhage. Intravitreal 1,000 centistokes (cs) SO was placed to prevent recurrent intraocular bleeding. No sutures were performed. During the first postoperative month, a progressive migration of SO into the $360^{\circ}$ subconjunctival space was noted until no intraocular SO was observed (Fig. 1). The patient had no symptoms and best-corrected visual acuity remained at no light perception in his left eye. Magnetic nuclear resonance was performed in order to rule out the presence of SO in the orbit. One month after surgery, SO was then incompletely removed from the subconjunctival space although attempts were made to withdraw all subconjunctival SO (Fig. 2). Sclerotomies were intraoperatively revised and no leakage was observed.

\section{Discussion}

Intraocular SO migration into the subconjunctival space through a glaucoma tube shunt or through unsutured sclerotomies has been previously reported [1-7]. In this particular case, a sutureless PPV and a pars plana tube GDD coexist, so the question is: Where did the subconjunctival SO come from?

It is interesting that massive extravasation of SO already occurred during the first month after its placement in the absence of oil emulsification. It is also remarkable that SO filled the $360^{\circ}$ subconjunctival space from the beginning of the migration and was not limited to the bleb or around the valve body. Slow emulsified SO migration through a GDD mature capsule and conjunctival tissue infiltration with $\mathrm{SO}$ has been described in the past for nonrestrictive devices $[1,2]$. A rare case of early and massive subconjunctival and orbital migration through an Ahmed glaucoma valve implant has also been reported when SO comes into contact with the tube and the capsule has not yet formed [3]. In our patient, the capsule was already formed 


\section{Case Reports in Ophthalmology}

\begin{tabular}{l|l} 
Case Rep Ophthalmol 2018;9:310-314 \\
\hline DOI: $10.1159 / 000487982$ & ๔ 2018 The Author(s). Published by S. Karger AG, Basel
\end{tabular} www.karger.com/cop

Téllez et al.: Massive Silicone Oil Migration into the Subconjunctival Space: A Leakage Mechanism Dilemma

and leakage could be explained by the presence of a pore in the mentioned capsule or a too broad scleral tunnel that allowed the oil to escape.

Replacing the tube in the posterior chamber to prevent contact with SO would have probably been the preferred option. Nevertheless, since the visual acuity of the patient was no light perception, we opted for conservative management in order to avoid greater manipulation.

The 23-gauge transconjunctival sutureless vitrectomy with SO injection is commonly accepted by vitreoretinal surgeons since its introduction in 2005 [8]. No massive SO migration has been reported up to date, although limited subconjunctival SO leakage occurs frequently after vitrectomy. Some reports describe tiny subconjunctival SO bubbles with an incidence of 8-10\%, sometimes with mild postoperative discomfort [4].

Silicone bubbles are usually difficult to detect at the slit lamp exam. Histopathological studies have demonstrated that small drops of silicone are found in $30 \%$ of eyes after sutureless PPV [5]. Our observations using Visante OCT after PPVs with SO injection confirm this frequency (data not published).

Viscosity of the SO may influence its leakage through the sclerotomy. With the advent of microincision PPV, surgeons usually prefer less viscous SO which can be introduced and removed more easily through the small cannulae. But the lower the viscosity, the lower the surface tension, so less viscous SO can easier pass through an unsutured sclerotomy than more viscous SO.

Reported cases of subconjunctival SO migration describe the use of 1,000 cs or viscosity is not specified. Probably the use of higher viscous SO may prevent its leakage.

The diameter of the hole through which SO has to pass is another important aspect to take into account. The microcannula has an internal diameter of $0.65 \mathrm{~mm}$ and an external diameter of $0.75 \mathrm{~mm}$. On the other hand, the tube of the Ahmed valve has an internal diameter of 0.3 $\mathrm{mm}$ and an external diameter of $0.63 \mathrm{~mm}$. GDDs have narrower diameters compared with cannulae in microincision PPV. Then, SO may migrate easier through sclerotomies than through the tube of the GDD in case both of them were open.

A main concern about SO leakage is the wound sealing. Some advices have been recommended in order to achieve a tight self-sealing wound at the end of the surgery: make the incision at about $30^{\circ}$ through the eye wall, minimizing the stretching of the sclera during surgical maneuvers, having a normal IOP before removing the microcannulae or use bipolar cautery in the conjunctiva over the wound [6]. Anyway, the safest maneuver is suture all sclerotomies when SO is used in order to avoid its leakage. Sometimes a loop suture is left in place and can be removed a few days after in the office.

Measures to control SO migration leakage, like tube removal or ligature, could be considered with high risk of IOP control loss. Modifying the tube placement in the inferotemporal quadrant of the anterior chamber can also be considered as an option but, as SO often takes many months to migrate, it is not usually performed in order to minimize manipulation.

Attempts to totally remove subconjunctival SO have limited success as infinite oil microdrops infiltrate subconjunctival tissues and fibrous septa usually appears.

In conclusion, the amount of SO migration, timing from surgery, and $360^{\circ}$ subconjunctival location suggest that an unsutured sclerotomy or a large defect in the capsule of the GGD may be the source of leakage in our patient. A lower threshold to check over GDD implants and suture sclerotomies in silicone cases is recommended. 


\section{Case Reports in Ophthalmology}

\begin{tabular}{l|l}
\hline Case Rep Ophthalmol 2018:9:310-314 \\
\hline DOI: 10.1159/000487982 & $\begin{array}{l}\text { C } 2018 \text { The Author(s). Published by S. Karger AG, Basel } \\
\text { www.karger.com/cop }\end{array}$ \\
\hline
\end{tabular}

Téllez et al:: Massive Silicone Oil Migration into the Subconjunctival Space: A Leakage Mechanism Dilemma

\section{Acknowledgements}

This case report was supported by the Department of Ophthalmology, Sant Pau Hospital.

\section{Statement of Ethics}

Written informed consent was obtained from the patient for publication of this case report and accompanying images. The datasets used and/or analyzed during the current study are available from the corresponding author on reasonable request.

\section{Disclosure Statement}

The authors declare that they have no competing interests.

\section{Author Contributions}

J.T. and J.I.V. clinically assessed, analyzed, and interpreted the patient data regarding the ocular manifestations. J.T. and J.I.V. were major contributors in writing the manuscript. All authors read and approved the final manuscript.

\section{References}

1 Hyung SM, Min JP: Subconjunctival silicone oil drainage through the Molteno implant. Korean J Ophthalmol 1998;12:73-75.

2 Chan KC, Tarasewicz DG, and Lin SG: Subconjunctival migration of silicone oil through a Baerveldt pars plana glaucoma implant. Br J Ophthalmol 2005;89:240-241.

-3 Nazemi PP, Chong LP, Varma R, et al: Migration of intraocular silicone oil into the subconjunctival space and orbit through an Ahmed glaucoma valve. Am J Ophthalmol 2001;132:929-931.

-4 Siqueira RC, Gil AD, Jorge R: Retinal detachment surgery with silicone oil injection in transconjunctival sutureless 23-gauge vitrectomy. Arq Bras Oftalmol 2007;70:905-909.

-5 Cunha LP, Primiano Júnior HP, Nakashima A, Trein Júnior JA, Ghanem RC, Santo RM, Nakashima Y Subconjunctival deposit of silicone oil after vitreoretinal surgery. Arq Bras Oftalmol 2007;70:589-592.

-6 Erakgun T, Egrilmez S: Surgical outcomes of transconjunctival sutureless 23-gauge vitrectomy with silicone oil injection. Indian J Ophthalmol 2009;57:105-109.

-7 Gorovoy IR, Stewart JM: $360^{\circ}$ subconjunctival silicone oil after unsutured 23-gauge vitrectomy. Eye 2013;27:894-895.

8 Eckardt C: Transconjunctival sutureless 23-gauge vitrectomy. Retina 2005;25:208-211. 


\section{Case Reports in Ophthalmology}

Case Rep Ophthalmol 2018;9:310-314 \begin{tabular}{l|l}
\hline DOI: 10.1159/000487982 & (c) 2018 The Author(s). Published by S. Karger AG, Basel
\end{tabular} www.karger.com/cop

Téllez et al.: Massive Silicone Oil Migration into the Subconjunctival Space: A Leakage Mechanism Dilemma

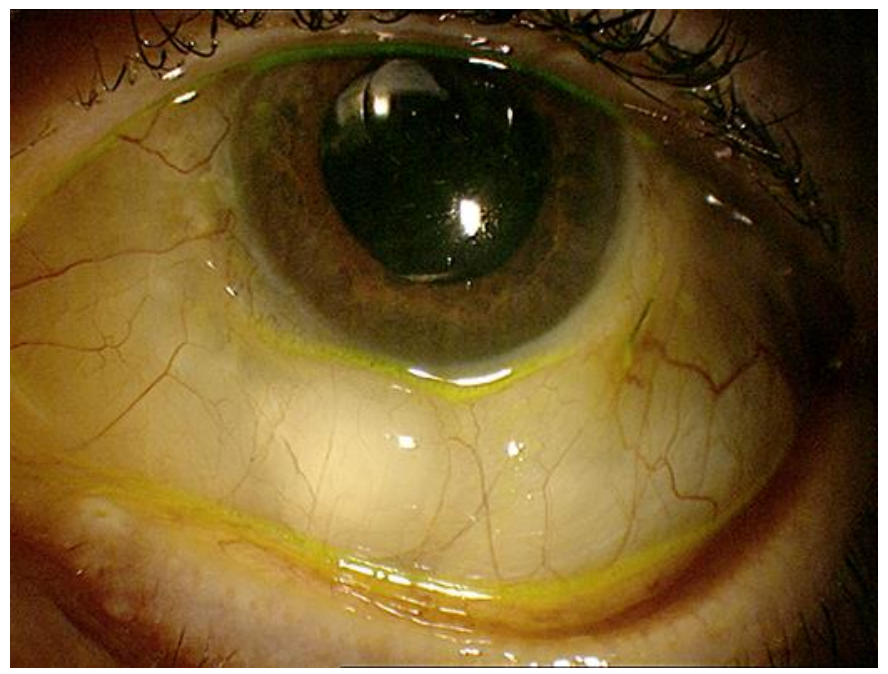

Fig. 1. Conjunctival appearance 3 weeks after pars plana vitrectomy and silicone oil injection. A big silicone oil bubble fills the subconjunctival space in the inferonasal quadrant.

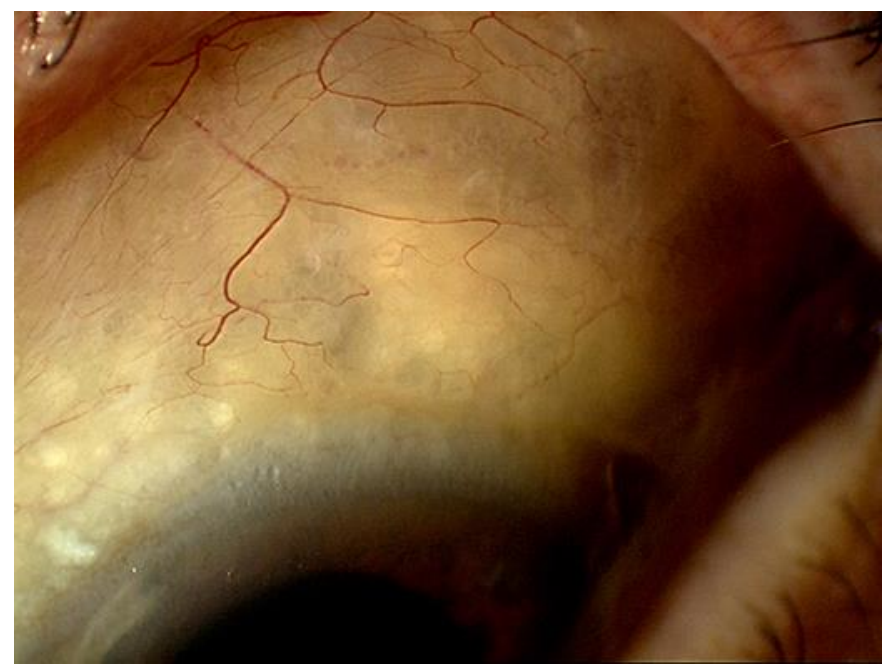

Fig. 2. Conjunctival appearance 2 months after pars plana vitrectomy and silicone oil injection. Countless silicone oil microbubbles fill the subconjunctival space in the superotemporal quadrant. 